\title{
Interdisciplinaridade e Ensino: Propostas para Planejamento Curricular
}

\section{Interdisciplinarity and Teaching: Proposals for Curricular Planning}

\author{
Renata Biguetti de Souza Santos ${ }^{\mathrm{a}}$; Givan José Ferreira dos Santos ${ }^{\mathrm{b}}$; Alessandra Dutra-Silva*bc
}

aSecretaria de Educação do Município de Londrina. PR, Brasil.

bUniversidade Tecnológica Federal do Paraná, Programas de Pós-Graduação Stricto Sensu em Ensino de Ciências Humanas, Sociais e da Natureza. PR, Brasil. 'Universidade Tecnológica Federal do Paraná, Programa de Pós-Graduação Stricto Sensu em Ensino de Ciência e Tecnologia. PR, Brasil.

*E-mail: alessandradutra@utfpr,edu.br

Recebido em: 02/07/19; Aceito em: 26/09/19

\begin{abstract}
Resumo
A questão do planejamento curricular se apresenta como um dos elementos centrais quando se reflete a respeito do complexo processo de ensino-aprendizagem escolar, particularmente da Educação Básica. Nessa perspectiva busca-se responder aos questionamentos por que fazer, o que é e como fazer um projeto de currículo para o ensino escolar com princípios da interdisciplinaridade e, em consonância com essa problemática, alcançar os objetivos de expor razões favoráveis à adoção na prática docente desse paradigma pedagógico, de mostrar alguns de seus traços conceituais e de sinalizar caminhos para sua efetivação. Com base em aspectos teóricos e metodológicos de pesquisadores sobre o fenômeno da interdisciplinaridade e sua relação com a organização curricular, empreendeu-se uma pesquisa de cunho bibliográfico, descritivo e analítico. Acredita-se que os pressupostos conceituais, as luzes pedagógicas e as reflexões apresentadas no trabalho possam contribuir para aprofundamento da compreensão do tema pelos atores sociais que pensam e atuam na educação do Brasil.
\end{abstract}

Palavras-chave: Processo de Ensino e Aprendizagem. Prática Docente. Educação no Brasil.

\begin{abstract}
The issue of curriculum planning is presented as one of the central elements when reflecting on the complex process of school teaching and learning, particularly in basic education. From this perspective, seeks to answer the questions why to do, what is and how to make a curriculum project for school teaching with interdisciplinary principles and, in line with this problem, achieve the objectives of exposing reasons favorable to adoption in practice. teacher of this pedagogical paradigm, to show some of its conceptual traits and to signal paths for its realization. Based on the theoretical and methodological aspects of researchers about the phenomenon of interdisciplinarity and its relationship with the curricular organization, a bibliographical, descriptive and analytical research was undertaken. It is believed that the conceptual assumptions, the pedagogical lights and the reflections presented in the work can contribute to the deepening of the understanding of the theme by the social actors who think and act in the education of Brazil.
\end{abstract}

Keywords: Teaching and Learning Process. Teaching Practice. Education in Brazil.

\section{Introdução}

Desde que começou o ensino formal de conhecimentos científicos, pesquisadores dos diversos países buscam construir propostas, alternativas para favorecer os processos de ensinar e aprender na escola. Na concretização do ensino escolar, vários elementos entram em ação - a formação do professor, o conhecimento prévio e o interesse da turma, a complexidade do conteúdo proposto para estudo, o planejamento das atividades, os suportes pedagógicos e tecnológicos utilizados, os procedimentos metodológicos adotados, entre outros - e influenciam, em alguma medida, a obtenção da meta principal que é a aprendizagem do aluno.

Tradicionalmente, o planejamento escolar tende a separar as disciplinas curriculares, por exemplo, Língua Portuguesa, Ciências, Geografia, História, Matemática, e cada disciplina foca o ensino de conteúdos / objetos de estudo de sua área, sem a preocupação de realizar relações, articulações com conhecimentos de outras disciplinas.

Nesse caso, trata-se de um planejamento curricular escolar multidisciplinar, em que cada componente curricular se justapõe um ou outro e elabora seu plano de trabalho docente para ensinar algo a seus alunos por intermédio de um único olhar científico. Numa perspectiva curricular contemporânea de organização do trabalho pedagógico, estudiosos defendem a adoção da postura de encontro, integração entre os professores de diferentes disciplinas, a fim de que aconteça um ensino ancorado na interdisciplinaridade, tendo como ponto de partida um planejamento curricular escolar interdisciplinar.

Dentro deste contexto, inserem-se as questões impulsionadoras desta pesquisa: Por que fazer, o que é e como fazer um planejamento com viés interdisciplinar? Em alinhamento a essa problemática, os objetivos do estudo são: expor argumentos favoráveis à adoção do planejamento curricular interdisciplinar em uma unidade escolar; explicitar traços característicos do planejamento curricular escolar interdisciplinar; e apresentar exemplos de caminhos para efetivação do planejamento curricular escolar interdisciplinar.

Embora desde 1971, a interdisciplinaridade, em suas muitas 
facetas, entre elas a questão do planejamento curricular, seja proposta nas leis educacionais, ela ainda é pouco conhecida e praticada na gestão escolar.

Portanto, um artigo que discuta questões sobre interdisciplinaridade, com foco no planejamento curricular, pode contribuir para a compreensão do tema e ativar reflexões produtivas, a fim da construção de uma educação interdisciplinar nas escolas brasileiras. Muitos professores admitem o desejo de trabalhar de modo mais conjunto, cooperativo com docentes de outras disciplinas escolares, entretanto alegam não saber como pensar e projetar a estruturação curricular de forma interdisciplinar. Nesse sentido, as reflexões deste artigo podem trazer subsídios para a formação dessa prática pedagógica.

\section{Material e Métodos}

Esta pesquisa caracteriza-se, basicamente, como bibliográfica, descritiva e analítica. O caráter bibliográfico se concretiza porque houve busca, seleção e uso de trabalhos e documentos publicados por estudiosos e instituições governamentais que discutem a realidade da implementação de princípios da interdisciplinaridade na (re)organização dos currículos escolares como alternativa contemporânea de qualificar o ensino.

O viés descritivo-analítico se efetiva nas respostas construídas para as três questões inspiradoras da investigação: Por que fazer, o que é e como fazer planejamento curricular escolar interdisciplinar? O artigo traz aportes teóricos e reflexivos referentes a razões, concepção e caminhos para a efetivação da interdisciplinaridade na organização do currículo nas escolas de educação básica.

\section{Resultados e Discussão}

Apesar de se reconhecer que, na prática docente, respostas para as questões por que fazer, o que é e como fazer planejamento curricular escolar interdisciplinar se efetivam de forma inter-relacionadas, amalgamadas, para fins didáticos é pertinente lançar um olhar mais centrado em cada um desses questionamentos, como se faz nas seções seguintes.

\subsection{Razões}

No cenário do ensino escolar de conhecimentos científicos, as ações pedagógicas docentes almejam criar situações propícias para aprendizagem dos alunos. Conforme dito antes, historicamente cada disciplina curricular buscou investigar, explicitar e discutir os objetos concretos e abstratos de estudo / da realidade, constituintes do universo interior ou exterior do ser humano, com base em teorias, conceitos, métodos, técnicas, linguagens e outros instrumentos específicos de sua disciplina, evitando, e muitas vezes até mesmo relegando, incorporar princípios e procedimentos de outras áreas consolidadas da ciência.

Esse caráter marcadamente monodisciplinar de investigação científica e ensino escolar vem sendo questionado por estudiosos (FAZENDA, 2002, 2013, 2013a, 2014; JAPIASSU, 1976; SANTOMÉ, 1998; MORIN, 2001; PASSOS; CHASSOT, 2013a; FERREIRA, 2013a), porque não leva em consideração o fenômeno da complexidade natural dos objetos/conhecimentos que, portanto epistemologicamente, induz ao entrosamento, diálogo, planejamento e trabalho curricular escolar interdisciplinar, pois essa valorização de vínculos entre diferentes disciplinas, em que, por exemplo, conceitos e métodos de uma possam ser aplicados em outra(s), oferece condições para a exploração de maior riqueza de aspectos de um mesmo objeto de conhecimento.

Essa visão integradora e macro é preconizada nas proposições a seguir:

[...] diferenças não constituem um impeditivo ao diálogo interdisciplinar, ao contrário, cada disciplina pode oferecer diferentes visões sobre um mesmo contexto, tornando-o mais enriquecedor. Todavia, não se pode, simplesmente, forçar um diálogo interdisciplinar sem que se questione a estruturação dos currículos no sentido de facilitar essa dialogicidade, o que deve ser uma reflexão permanente entre educadores, órgãos governamentais e sociedade em geral (SANTOS et al., 2016, p.154).

Pensar os objetos de ensino de maneira a articulá-los e alinhá-los nas disciplinas da matriz curricular implica na reflexão crítica de práticas pedagógicas costumeiras e nova ressignificação do processo de elaboração e consecução do programa escolar e do plano de trabalho docente, em função do objetivo de impactar positivamente a aprendizagem dos alunos, logo, contribuir para a melhoria da qualidade da educação do país. Essa perspectiva interdisciplinar é ressaltada por diversos documentos oficiais que orientam a educação básica no Brasil (BRASIL, 1996, 1998, 2013, 2016).

Outra consideração computada à adoção de um planejamento curricular escolar interdisciplinar apoia-se na necessidade de reconfiguração do próprio sistema de ensino, da práxis educativa, em decorrência do novo perfil do sujeito aluno-aprendiz das últimas décadas, originado pelas avassaladoras mudanças nas complexas estruturas do modo de gerar, circular e recepcionar conhecimentos científicos num mundo cada vez mais globalizado e tecnológico.

Esse modelo de planejamento organiza o currículo de maneira a estabelecer relações produtivas entre os saberes de campos científicos diversos, possibilitando novos padrões cognitivos e de raciocínio, quer dizer, o desenvolvimento de novas competências e habilidades, para o indivíduo aluno compreender, interpretar e questionar, numa condição mais holística e menos compartimentalizada, esses mesmos saberes propostos nas aulas pelas disciplinas.

\subsection{Concepção}

A concepção que conduzirá a organização curricular do trabalho pedagógica se impõe como um dos aspectos de maior relevância e desafio para as instituições escolares e os profissionais do ensino. Visto que no decorrer da história, 
em geral a formação dos professores se baseia na ideia de que cada área do saber - Matemática, Física, Química, História, Geografia, Letras / Língua Portuguesa e Literatura, entre outras - deve se ater exclusivamente a um conjunto de conhecimentos específicos de seu domínio, prevalecia, e prevalece, o pensamento pedagógico de que cada disciplina escolar tem sua identidade e especificidade e não deve se intrometer em investigar objetos de estudo de outras disciplinas. Os ditos populares "cada macaco no seu galho" e "cada conhecimento na sua caixinha" traduzem bem essa práxis.

Essa visão segmentada de educação evidencia um distanciamento contraproducente entre as disciplinas que compõem o currículo, levando até mesmo à discriminação, na qual certa(s) disciplina(s) se apregoa(m) mais importante(s) que outras para a formação científica do aluno. Assim, justifica-se não haver necessidade de reunião pedagógica entre professores de diferentes disciplinas, pois basta que o professor de cada área faça separadamente seu planejamento de conteúdos e atividades curriculares e os apresente ao responsável pela orientação ou gestão pedagógica da escola.

Na constituição do planejamento curricular a partir de uma falta de aproximação e diálogo entre professores de campos distintos de saber humano, perde-se a oportunidade de uma área incorporar contribuições teóricas e práticas de outras áreas, enriquecendo com a possibilidade de complementaridade de saberes. E mais, deixa-se de aproveitar situação propícia para problematizar e discutir aspectos comuns a diferentes disciplinas que integram o currículo, que poderiam levar à ampliação de conhecimentos científicos, com consequente benefício para o aprendizado dos alunos.

A perspectiva de separar estreitamente os conhecimentos em campos específicos e isolados na organização do trabalho pedagógico prioriza o processo de ensino-aprendizagem do alunado com base em atividades de cunho marcadamente analítico, ou seja, não favorece a possibilidade para que os estudantes aprendam com ancoragem no pensamento sincrético, isto é, abrangente e integrador, impulsionado pela "cooperação e coordenação crescente entre as disciplinas" (FAZENDA, 2002, p.38).

Por outro lado, contemporaneamente, especialistas da educação orientam que o planejamento curricular é o momento propício para que professores de diferentes disciplinas e os responsáveis pela coordenação pedagógica na escola se reúnam e, a partir de um paradigma interdisciplinar, projetem o processo formativo dos alunos. Isso significa que o professor de uma determinada disciplina se dispõe a pensar como os conteúdos específicos de sua área podem se articular, de modo produtivo, com conteúdos próprios de outras disciplinas, a fim de que o aluno possa ter sua possibilidade de aprendizagem científica ampliada a respeito de um mesmo objeto de estudo. Esta concepção caracteriza-se como planejamento curricular escolar interdisciplinar.

Essa abordagem deve ser feita através de um diálogo aberto, profundo e verdadeiro entre os protagonistas do planejamento curricular, em que cada protagonista não deve buscar vangloriar-se em relação aos demais do grupo pensante, mas colocar-se essencialmente num sentimento de comprometimento e respeito com o grupo, imprimindo sim sua singularidade de posições e proposições, mas buscando impreterivelmente espaços de encontro e relação com os outros, com a aspiração de possibilitar ao aluno o desenvolvimento de novos saberes alicerçado no trabalho interdisciplinar. Com atenção a essas características, efetivam-se a integração e a qualidade da ação pedagógica no conjunto de diferentes disciplinas que compõe o currículo escolar, resultando em um planejamento com mentalidade inclusiva, personalizada, reflexiva e colaborativa.

\subsection{Discussão}

Pretende-se nesta seção discutir e propor caminhos, formas de concretização dos princípios interdisciplinares na sistematização dos saberes científicos nos currículos das escolas. Primeiramente, é oportuno reiterar que os quadros teóricos e metodológicos, nas universidades, não propõem na formação profissional dos professores estudos de como deslocar os docentes de um planejamento curricular educacional baseado num patamar estreitamente disciplinar para formas de organização de currículo e tratamento de conteúdos científicos em moldes interdisciplinares. Importa reconhecer também a escassez de publicações científicas no Brasil de trabalhos com relato e explicitação de experiências com modos de pensar e intervir interdisciplinarmente no ensino escolar.

Diante desse panorama, é compreensível a falta de ânimo e, muitas vezes, a aversão dos professores quando se apresenta a proposição de encontros formais para se refletir e discutir propostas de planejamento curricular escolar interdisciplinar. Esse dilema se dá em todos os níveis de escolaridade e com docentes de todas as áreas da ciência. Portanto, de fato, a implementação de uma educação interdisciplinar nas escolas brasileiras, como projeta as leis educacionais do país, constitui um grande desafio. $\mathrm{O}$ que se nota na prática são iniciativas e estratégias próprias de algumas escolas públicas ou particulares que buscam formas inovadoras de intervenção educativa e acabam se tornando vetores no meio educacional, como é o exemplo do Sistema SESI de Ensino.

O caso da unidocência dos professores, que atuam nos Anos Iniciais do Ensino Fundamental, em que um mesmo professor exerce a docência de diversas disciplinas em uma mesma turma, favorece a possibilidade de professores de uma mesma série/ano escolar reunirem-se para organizar os conteúdos curriculares na concepção interdisciplinar. Adiante apresenta-se um o planejamento sobre o eixo temático "Brinquedos e brincadeiras infantis", possível de ser implementado no Terceiro Ano do Ensino Fundamental, com vistas ao trabalho integrado e entre diferentes disciplinas da matriz curricular. 
Figura 1 - Planejamento curricular escolar interdisciplinar para o terceiro ano do Ensino Fundamental a partir do eixo temático

História: história dos brinquedos e brincadeiras no Brasil e o combate a preconceitos

Língua Portuguesa: atividades orais e escritas diversas sobre o tema (leitura de livros infantis, roda de conversa, dramatização, produção de texto com instrução de como montar um brinquedo e de texto com regras de participação em brincadeira, produção individual final de um portifólio com os textos elaborados no conjunto de disciplinas)

年

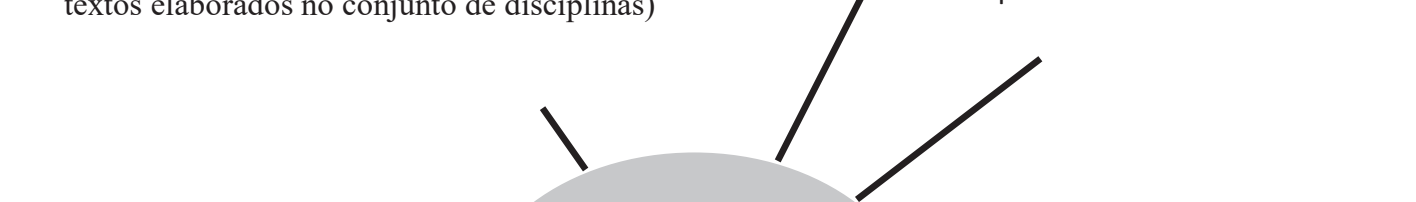

Matemática: números, formas, pesos , porcentagem, operações de soma e subtração

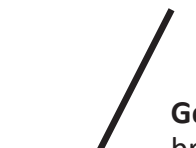

Geografia: brinquedos e brincadeiras nas diversas regiões do país e suas influências sociais
Ciências: estudo da física e da química dos brinquedos e brincadeiras; benefícios e prejuízos dos brinquedos e brincadeiras para a saúde/transformação do corpo
Arte: montagem de brinquedos com uso de estratégias diversas (desenho, colagem, recorte, modelagem, dobradura, ...) e reflexão sobre o direito de brincar na infância

Fonte: Dados da pesquisa.

O entrelaçamento de conteúdos e atividades mostrados no planejamento da Figura 1 busca uma articulação qualitativa entre as disciplinas, proporcionando ao aluno um múltiplo olhar sobre o fio temático investigado, a aprendizagem de vários aspectos sobre o mesmo objeto de estudo, de modo a compor uma visão mais macro e crítica. Cabe ressaltar que trata-se de uma sugestão de planejamento, portanto, a escolha dos saberes a serem explorados em cada disciplina, a maneira de organizar as atividades, o maior ou menor grau de conexão entre as disciplinas, o tempo de duração de trabalho pedagógico sobre o tema integrador, entre outros elementos envolvidos na ação educativa, dependerão da formação dos professores, dos objetivos da escola, das condições oferecidas pela instituição de ensino e de outros fatores condicionantes do contexto educacional. Assim adaptações e aprimoramentos às situações reais de ensino não só são esperados, como necessários.

Outro caminho de diversas áreas do saber científico planejar intervenções pedagógicas de modo interdisciplinar é a partir da identificação de um problema social relevante para a comunidade escolar / grupo de alunos sujeito da aprendizagem. Os professores de diferentes disciplinas de uma determinada série/ano escolar se juntam, dialogam e definem o problema social a ser estudado com os alunos.
Então, projetam conexões interdisciplinares de conteúdos, métodos, textos, linguagens, entre outras possibilidades, com vista ao aprendizado contextualizado e significativo para o aluno.

Nesse sentido, promove-se desde a etapa de planejamento um olhar globalizante e pluralista de áreas distintas do conhecimento científico a respeito do objeto de estudo. Com efeito, planejar e trabalhar com a interdisciplinaridade significa legitimar a autonomia e as particularidades de cada disciplina de ensino, contudo oportuniza-se o estabelecimento de relações e partilhas produtivas entre as disciplinas, para a otimização do processo ensino-aprendizagem, como destacado na seguinte diretriz:

A interdisciplinaridade não dilui as disciplinas, ao contrário, mantém sua individualidade. Mas integra as disciplinas a partir da compreensão das múltiplas causas ou fatores que intervêm sobre a realidade e trabalha todas as linguagens necessárias para a construção de conhecimentos, comunicação e negociação de significados e registro sistemático dos resultados (BRASIL, 1989, p.89).

$\mathrm{Na}$ Figura 2, exposta mais à frente, projeta-se uma proposta de sistematização interdisciplinar tendo como foco o estudo sobre o uso prejudicial de tecnologias digitais, por exemplo, o celular e o computador, entre adolescentes e jovens. 
Figura 2 - Planejamento curricular escolar interdisciplinar para anos finais do Ensino Fundamental ou anos do Ensino Médio a partir de um problema social relevante

Língua Estrangeira: textos, linguagens e tecnologias característicos empregados em suportes digitais e discussão sobre o uso funcional
Ciências: estudo da Física e da Química das tecnologias digitais e possíveis prejuízos a saúde; uso de tecnologias no ensino escolar

Filosofia e Sociologia: concepção de tecnologia e humanismo e suas implicações epstemológicas, sociais e políticas no pensamento e comportamento humano

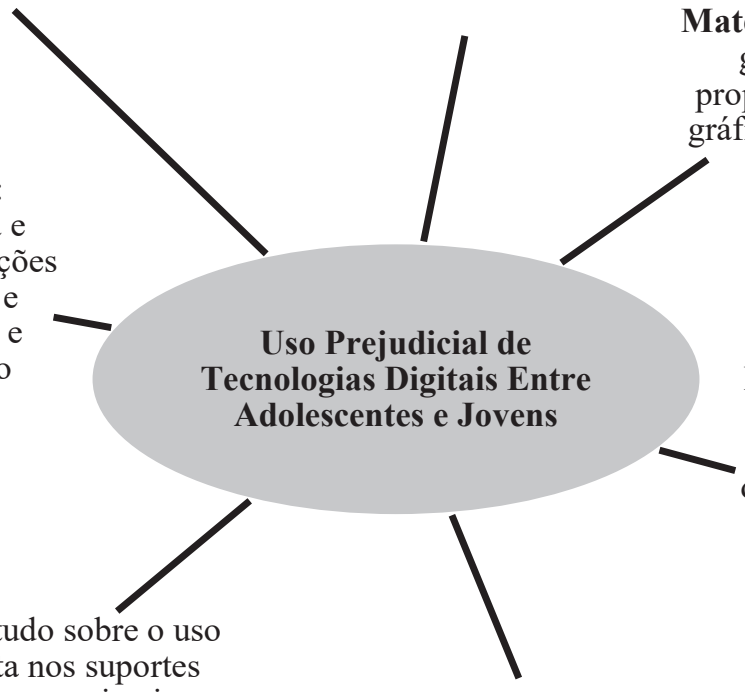

Matemática: formas geométricas, proporcionalidade, gráficos, volume, ...

Língua Portuguesa: estudo sobre o uso da oralidade e da escrita nos suportes digitais; produção de textos opinativos (seminário, ensaio) a respeito de polêmicas referentes ao tema; compreensão e produção de textos digitais significativos (infográfico, comentário online, propaganda digital)

Fonte: Dados da pesquisa.

Esta temática/problemática pode ser produtiva para trabalhos em anos finais do Ensino Fundamental e também nos anos do Ensino Médio, com pertinentes ajustes às realidades escolares.

\section{Conclusão}

Com explicações teóricas, exemplificações e posicionamentos reflexivos apresentados no decorrer deste estudo, acredita-se ter construído respostas plausíveis para as questões deflagradoras da pesquisa (Por que fazer, o que é e como fazer planejamento curricular escolar interdisciplinar?) e para os objetivos traçados (Expor argumentos favoráveis à adoção do planejamento curricular escolar interdisciplinar; Explicitar traços característicos do planejamento curricular escolar interdisciplinar; Apresentar exemplos de caminhos para efetivação do planejamento curricular escolar interdisciplinar).

Reafirma-se que, no atual contexto do ensino escolar, o implemento de projetos interdisciplinares constitui desafio e ousadia e requer que órgãos governamentais e gestores da educação promovam cursos de formação dos profissionais inicial ou continuada - envolvidos no processo de ensino e aprendizagem, a fim de que eles se apropriem de conhecimentos teóricos e práticos sobre essa perspectiva pedagógica. Embora se reconheçam as dificuldades para a viabilização de planejar os conteúdos curriculares na escola pela via interdisciplinar, estudos recentes acenam a necessidade de mudanças na forma de pensar, projetar e intervir no ensino em razão das novas competências cognitivas exigidas no mundo atual, com o propósito de impactar positivamente a aprendizagem dos alunos. Os princípios da interdisciplinaridade se apresentam como uma possibilidade transformadora e produtiva. Foi no sentido de contribuir com orientações teóricas e reflexões sobre o tema e de lançar luzes para possíveis caminhos a serem trabalhados que se propôs este artigo.

\section{Referências}

BRASIL. Ministério da Educação. Secretaria de Educação Infantil. Referencial Curricular Nacional para Educação Infantil. Brasília: MEC/SEF, 1989.

BRASIL. Ministério da Educação e do Desporto. Lei nº 9.394, de 20 de dezembro de 1996. Estabelece as diretrizes e bases da educação nacional. Diário Oficial da União, Brasília, DF, 23 dez. 1996. Disponível em:

http://www.planalto.gov.br/ccivil_03/leis/L9393.htm. Acesso em 19 dez. 2018.

BRASIL. Secretaria de Educação Fundamental. Parâmetros curriculares nacionais: terceiro e quarto ciclos do Ensino Fundamental. Secretaria de Educação Fundamental. Brasília: 


\section{MEC/SEF, 1998.}

BRASIL. Ministério da Educação. Secretaria de Educação Básica. Secretaria de Educação Continuada, Alfabetização, Diversidade e Inclusão. Diretrizes Curriculares Nacionais da Educação Básica. Brasília: MEC/SEB; DICEI, 2013. Disponível em:

http://portal.mec.gov.brindex.php?option=com docman \&view $=$ download \&alias $=13448$-diretrizes-curricularesnacionais-2013-pdf\&ltemid=30192. Acesso em 19 dez. 2018 .

BRASIL. Ministério da Educação. Base Nacional Comum Curricular - BNCC $3^{\text {a }}$ versão. Brasília, DF, 2017. Disponível em:

http://basenacionalcomum.mec.gov.br/imagens/pdf/0_BNCCFinal_Apresentação.pdf. Acesso em: 19 dez. 2018.

FAZENDA, I. C. A. Integração e interdisciplinaridade no ensino brasileiro: efetividade ou ideologia. São Paulo: Loyola, 2002.

FAZENDA, I.C.A. (Org.). O que é interdisciplinaridade? São Paulo: Cortez, 2013.

FAZENDA, I.C.A. (Coord.). Práticas interdisciplinares na escola. São Paulo: Cortez, 2013.
FAZENDA， I.C.A. (Org.). Interdisciplinaridade: pensar, pesquisar e intervir. São Paulo: Cortez, 2014.

FERREIRA, M.H.M.P. Ciência e interdisciplinaridade. In: FAZENDA, I.C.A. (Coord.) Práticas interdisciplinares na escola. São Paulo: Cortez, 2013.

JAPIASSU, H. Interdisciplinaridade e patologia do saber. Rio de Janeiro: Imago, 1976.

PASSOS, L.F.; CHASSOT, M.F. Interdisciplinaridade, competência e escola pública. In: FAZENDA, I. C. A. (Coord.) Práticas interdisciplinares na escola. São Paulo: Cortez, 2013.

SANTOS, M.L. et al. Análise de alimentos: contextualização e interdisciplinaridade em cursos de formação continuada. Quím. Nova Escola, v.38, n.2, p.149-156, 2016.

SANTOMÉ, J.T. Globalização e interdisciplinaridade: o currículo integrado. Porto Alegre: Artmed, 1998.

MORIN, E. A religação dos saberes: o desafio do século XXI. Rio de Janeiro: Bertrand Brasil, 2001. 